\title{
Arterial Healing 10 Months After Implantation of an Ultrathin-Strut, Biodegradable-Polymer, Sirolimus-Eluting Stent
}

- An Angioscopic Study -

\author{
Takuya Tsujimura, MD; Takayuki Ishihara, MD; Osamu Iida, MD; \\ Yosuke Hata, MD; Taku Toyoshima, MD; Naoko Higashino, MD; \\ Naoya Kurata; Mitsutoshi Asai, MD, PhD; Masaharu Masuda, MD, PhD; \\ Shin Okamoto, MD; Kiyonori Nanto, MD; Takashi Kanda, MD; \\ Yasuhiro Matsuda, MD; Toshiaki Mano, MD, $\mathrm{PhD}$
}

\begin{abstract}
Background: The OrsiroTM ultrathin-strut, biodegradable-polymer, sirolimus-eluting stent (O-SES) has specific characteristics regarding its components and has demonstrated comparable clinical outcomes compared with durable-polymer, drug-eluting stents (DES). However, arterial repair following deployment of the O-SES has not been elucidated to date.
\end{abstract}

\begin{abstract}
Methods and Results: Using data from the Kansai Rosai Hospital database between November 2010 and September 2020, we analyzed coronary angioscopy (CAS) findings a mean $( \pm S D)$ of $10 \pm 2$ months after implantation of an O-SES, a durable-polymer everolimus-eluting stent (Xience ${ }^{\mathrm{TM}}$; X-EES), or a biodegradable-polymer everolimus-eluting stent (Synergy ${ }^{\mathrm{TM}}$; S-EES). Neointimal coverage (NIC), yellow color intensity of the stented segment, and the incidence of thrombus adhesion were compared between the O-SES (66 stents from 42 patients), X-EES (119 stents from 87 patients), and S-EES (132 stents from 88 patients). NIC was significantly thinner for the O-SES than S-EES $(P<0.001)$, but was similar between the O-SES and $X$-EES $(P=0.25)$. Yellow color intensity was significantly greater for the O-SES than $X$-EES $(P<0.001)$, but similar between the O-SES and $S$-EES $(P=0.51)$. The incidence of thrombus adhesions was similar in all 3 groups.
\end{abstract}

Conclusions: O-SES and X-EES resulted in similar inhibition of NIC and both resulted in a thinner NIC than with S-EES. In addition, O-SES exhibited a similar degree of thrombus adhesion as the other DES, suggesting similar thrombogenicity.

Key Words: Angioscopy; Coronary artery disease; Drug-eluting stent

$\mathbf{T}$ he availability of drug-eluting stents (DES) has markedly decreased the incidence of restenosis compared with bare-metal stents by inhibiting neointimal proliferation. ${ }^{1}$ However, delayed healing and abnormal vascular responses, including neoatherosclerosis, often occurred after implantation of first-generation DES, which contributed to late and very late stent thrombosis. ${ }^{2,3}$ Although compared with first-generation DES, the use of second-generation durable-polymer (DP) DES led to improved clinical outcomes up to 5 years after implantation, ${ }^{4}$ the issue of neoatherosclerosis has remained unresolved even with second-generation DES; one factor contributing to neoatherosclerosis is thought to be the polymer used in the DES.5,6 In order to overcome such limitations, biode- gradable-polymer (BP) DES have been developed, with reported clinical outcomes similar to those of DP-DES., ${ }^{7,8}$ The Orsiro ${ }^{\mathrm{TM}}$ ultrathin-strut, BP, sirolimus-eluting stent (O-SES; Biotronik, Bülach, Switzerland) is a BP-DES with specific characteristics regarding its components: (1) it has an ultrathin-strut with a thickness of only $60 \mathrm{~mm}$ (in stents $\leq 3.0 \mathrm{~mm}$ ) or $80 \mathrm{~mm}$ (in stents $\geq 3.5 \mathrm{~mm}$ ); (2)the stent surface is fully coated with a layer of amorphous hydrogen-rich silicon carbide acting as a diffusion barrier (Probio ${ }^{\mathrm{TM}}$ ), sealing the bare-metal surface and reducing ion release; (3) the drug is released over 12-14 weeks; and (4) the polymer is completely degraded over $12-24$ months, which is longer than for other BP-DES such as the Synergy ${ }^{\mathrm{TM}} \mathrm{BP}$, everolimus-eluting stent (S-EES; Boston Scientific, Nattick, MA,

Received May 6, 2021; accepted May 6, 2021; J-STAGE Advance Publication released online May 29, 2021 Time for primary review: 1 day

Kansai Rosai Hospital Cardiovascular Center, Amagasaki (T. Tsujimura, T.I., O.I., Y.H., T. Toyoshima, N.H., M.A., M.M., S.O., K.N., T.K., Y.M., T.M.); Department of Clinical Engineering, Kansai Rosai Hospital, Amagasaki (N.K.), Japan

Mailing address: Takayuki Ishihara, MD, Kansai Rosai Hospital Cardiovascular Center, 3-1-69 Inabaso, Amagasaki 660-8511, Japan. E-mail: t.ishihara31@gmail.com

All rights are reserved to the Japanese Circulation Society. For permissions, please e-mail: cr@j-circ.or.jp

ISSN-2434-0790 


\begin{tabular}{|c|c|c|c|c|c|}
\hline & \multirow{2}{*}{$\begin{array}{l}\text { O-SES } \\
(n=42)\end{array}$} & \multirow{2}{*}{$\begin{array}{l}\text { X-EES } \\
(\mathrm{n}=87)\end{array}$} & \multirow{2}{*}{$\begin{array}{l}\text { S-EES } \\
(\mathrm{n}=88)\end{array}$} & \multicolumn{2}{|c|}{$P$ value } \\
\hline & & & & O-SES vs. X-EES & O-SES vs. S-EES \\
\hline Age (years) & $71 \pm 11$ & $71 \pm 9$ & $68 \pm 12$ & 0.95 & 0.15 \\
\hline Male sex & $34(81)$ & $71(82)$ & $71(81)$ & 0.93 & 0.97 \\
\hline Hypertension & $24(57)$ & $66(76)$ & $63(72)$ & 0.030 & 0.10 \\
\hline Dyslipidemia & $29(69)$ & $59(68)$ & $57(65)$ & 0.89 & 0.63 \\
\hline Diabetes & $23(55)$ & $34(39)$ & 27 (31) & 0.093 & 0.008 \\
\hline Current smoker & $14(33)$ & $15(17)$ & $28(32)$ & 0.040 & 0.86 \\
\hline Hemodialysis & $2(5)$ & $1(1)$ & $1(1)$ & 0.20 & 0.20 \\
\hline Prior PCl & $21(50)$ & $46(53)$ & $32(36)$ & 0.76 & 0.14 \\
\hline Prior $\mathrm{CABG}$ & $1(2)$ & $1(1)$ & $1(1)$ & 0.60 & 0.59 \\
\hline
\end{tabular}

Unless indicated otherwise, data are presented as the mean \pm SD or $n(\%)$. CABG, coronary artery bypass grafting; O-SES, ultrathin-strut biodegradable-polymer sirolimus-eluting stent (Orsiro $\left.{ }^{\mathrm{TM}}\right)$; $\mathrm{PCl}$, percutaneous coronary intervention; S-EES, biodegradable-polymer everolimus-eluting stent (Synergy ${ }^{\mathrm{TM}}$ ); X-EES, durable-polymer everolimuseluting stent $\left(\right.$ Xience $\left.^{\mathrm{TM}}\right)$.

USA) or the Ultimaster ${ }^{\mathrm{TM}} \mathrm{BP}$, sirolimus-eluting stent (U-SES; Terumo Corporation, Tokyo, Japan). ${ }^{9}$ Therefore, it is possible that the process of arterial healing after O-SES implantation differs to that after implantation of DP-DES and the other BP-DES. However, few studies have compared intravascular status after O-SES implantation with that following DP-DES or other BP-DES implantation. In evaluating arterial healing, it is important to assess intravascular status using intravascular imaging devices. Of these, coronary angioscopy (CAS) is the only imaging modality that allows observation of intrastent status by direct and full-color visualization. ${ }^{10-18}$ Thus, in the present study, we used CAS to evaluate arterial healing after implantation of O-SES compared with DP-DES and other BP-DES.

\section{Methods}

\section{Patients}

This was a single-center retrospective observational study. We extracted CAS findings from the Kansai Rosai Hospital database between November 2010 and September 2020 for patients with an O-SES, a DP everolimus-eluting stent (Xience $^{\mathrm{TM}}$ [X-EES]; Abbott Vascular, Abbott Park, IL, USA), or an S-EES a mean ( \pm SD) of $10 \pm 2$ months after implantation (a total of 317 stents in 264 lesions from 217 patients). We then compared the CAS findings of O-SES (66 stents in 50 lesions from 42 patients) with those of X-EES (119 stents in 103 lesions from 87 patients) and S-EES (132 stents in 111 lesions from 88 patients). All DES were implanted into de novo lesions in native coronary arteries. We excluded patients who had had any event of earlier stent failure, such as in-stent restenosis, or for whom successful angioscopic evaluation was not possible.

Although angioscopic evaluation was recommended for all patients at follow-up angiography, as well as staged percutaneous coronary intervention (PCI) for other lesions, this was not performed when informed consent could not be obtained, or when an expert specialist for angioscopic evaluation was not available. Patients electing to undergo the procedure were given ticlopidine $(200 \mathrm{mg} / \mathrm{day})$, clopidogrel $(75 \mathrm{mg} /$ day $)$, or prasugrel $(3.75 \mathrm{mg} /$ day $)$ in addition to aspirin $(100 \mathrm{mg} /$ day) at least 1 week before PCI. For emergency patients, the antiplatelet drugs $(200 \mathrm{mg}$ aspirin and $300 \mathrm{mg}$ clopidogrel or $20 \mathrm{mg}$ prasugrel) were given before PCI. Most patients continued to receive dual anti- platelet therapy during the follow-up period according to the guidelines current at that time. ${ }^{19}$

The Medical Ethics Committee of Kansai Rosai Hospital approved the study, and all patients had provided written informed consent. This study was performed in accordance with the Declaration of Helsinki and the ethical standards of the responsible committee on human experimentation.

\section{Angiographic and Angioscopic Follow-up}

CAS was performed after administration of unfractionated heparin $(5,000 \mathrm{IU})$ into the radial or femoral artery via the inserted sheath, and isosorbide dinitrate into the coronary artery. CAS was subsequently performed between November 2010 and September 2016 using a Fullview NEO angioscopic catheter (FiberTech, Tokyo, Japan), as described previously. ${ }^{10,11}$ Briefly, an optical fiber was placed at the distal segment of the coronary artery and manually pulled back from the distal edge of the stent to the proximal edge under careful angioscopic and angiographic guidance. Since October 2016, a smart-i angioscopic catheter (Surgetech Corp., Tokyo, Japan) has been used after the Fullview NEO was discontinued. Using guide extension catheters such as GuideLiner (Japan Lifeline, Tokyo Japan), Guidezilla (Boston Scientific), and guideplus (NIPRO, Osaka, Japan), blood flow was blocked by flushing with low molecular weight dextran. Angioscopic images obtained using both types of angioscopic catheter were of 3,000 pixels in full color and were digitally stored for off-line analysis. Furthermore, a forward-looking angioscopic catheter (OVALIS, Osaka, Japan), which can project images with 9,000 pixels, and a smart-i $6 \mathrm{~K}$ angioscopic catheter (Surgetech Corp.), which can project images with 6,000 pixels, have been available since August 2018 and October 2018 , respectively. These catheters were used in some cases after those dates.

\section{Angioscopic Analysis}

Angioscopic images were analyzed to determine: (1) the dominant degree of neointimal coverage (NIC) over the stent; (2) heterogeneity of NIC; (3) the yellow color grade of the stented segment; and (4) the presence of an intrastent thrombus.

NIC over the stent was classified into 4 grades as described previously: Grade 0, stent struts fully visible, similar to immediately after implantation; Grade 1, stent struts bulging 


\begin{tabular}{|c|c|c|c|c|c|}
\hline & \multirow{2}{*}{$\begin{array}{l}\text { O-SES } \\
(n=42)\end{array}$} & \multirow{2}{*}{$\begin{array}{l}X-E E S \\
(n=87)\end{array}$} & \multirow{2}{*}{$\begin{array}{l}\text { S-EES } \\
(n=88)\end{array}$} & \multicolumn{2}{|c|}{$P$ value } \\
\hline & & & & O-SES vs. X-EES & O-SES vs. S-EES \\
\hline Aspirin & $42(100)$ & $81(93)$ & $84(96)$ & 0.081 & 0.16 \\
\hline $\mathrm{P}_{2} \mathrm{Y}_{12}$ inhibitor & $38(91)$ & $79(91)$ & $83(94)$ & 0.95 & 0.42 \\
\hline Cilostazol & $1(2)$ & $1(1)$ & $0(0)$ & 0.60 & 0.15 \\
\hline Warfarin & $3(7)$ & $4(5)$ & $1(1)$ & 0.55 & 0.064 \\
\hline DOAC & $1(2)$ & $9(10)$ & $3(3)$ & 0.11 & 0.75 \\
\hline Statin & $39(93)$ & $63(62)$ & $67(76)$ & 0.007 & 0.022 \\
\hline EPA & $4(10)$ & $11(13)$ & $9(10)$ & 0.60 & 0.90 \\
\hline
\end{tabular}

Unless indicated otherwise, data are presented as $\mathrm{n}(\%)$. DOAC, direct oral anti-coagulant; EPA, eicosapentaenoic acid. Other abbreviations as in Table 1.

\begin{tabular}{|lccccc|}
\hline Table 3. Lesion Characteristics & & & & & \\
& O-SES & X-EES & S-EES & \multicolumn{2}{c|}{ P value } \\
\cline { 5 - 6 }$(\mathbf{n = 5 0 )}$ & $(\mathbf{n = 1 0 3 )}$ & $(\mathbf{n = 1 1 1 )}$ & O-SES vs. X-EES & O-SES vs. S-EES \\
ACS & $16(32)$ & $22(21)$ & $37(33)$ & 0.15 & 0.87 \\
Lesion location & & & & 0.99 & 0.58 \\
LAD & $21(42)$ & $43(42)$ & $47(42)$ & & \\
LCX & $13(26)$ & $27(26)$ & $21(19)$ & & \\
RCA & $16(32)$ & $33(32)$ & $43(39)$ & & 0.25 \\
CTO & $1(2)$ & $7(7)$ & $7(6)$ & 0.21 & 0.26 \\
Ostial lesion & $2(4)$ & $10(10)$ & $10(9)$ & 0.22 & 0.39 \\
Bifurcation & $23(46)$ & $36(35)$ & $43(39)$ & 0.19 & 0.99 \\
Calcification & $4(8)$ & $17(17)$ & $21(19)$ & 0.15 & \\
ACC/AHA classification A & & & & & \\
Type A & $3(6)$ & $10(10)$ & $6(5)$ & & \\
Type B1 & $6(12)$ & $24(23)$ & $14(13)$ & & \\
Type B2 & $11(22)$ & $18(17)$ & $23(21)$ & & \\
Type C & $30(60)$ & $51(50)$ & $68(61)$ & & \\
\hline
\end{tabular}

Unless indicated otherwise, data are presented as $\mathrm{n}(\%)$. ${ }^{\mathrm{B} B a s e d}$ on the American College of Cardiology/American Heart Association (ACC/AHA) classification. ACS, acute coronary syndrome; CTO, chronic total occlusion; LAD, left anterior descending artery; LCX, left circumflex artery; RCA, right coronary artery. Other abbreviations as in Table 1.

\begin{tabular}{|c|c|c|c|c|c|}
\hline & \multirow{2}{*}{$\begin{array}{l}\text { O-SES } \\
(n=66)\end{array}$} & \multirow{2}{*}{$\begin{array}{c}X-E E S \\
(n=119)\end{array}$} & \multirow{2}{*}{$\begin{array}{l}\text { S-EES } \\
(n=132)\end{array}$} & \multicolumn{2}{|c|}{$P$ value } \\
\hline & & & & O-SES vs. X-EES & O-SES vs. S-EES \\
\hline Intravascular imaging device & & & & $<0.001$ & 0.015 \\
\hline Intravascular ultrasound & $36(55)$ & $94(79)$ & $95(72)$ & & \\
\hline Optical coherence tomography & $30(45)$ & $25(21)$ & $37(28)$ & & \\
\hline Predilatation & $55(83)$ & $85(71)$ & $111(84)$ & 0.071 & 0.89 \\
\hline $\begin{array}{l}\text { Maximum predilatation balloon } \\
\text { diameter }(\mathrm{mm})\end{array}$ & $2.3 \pm 0.8$ & $2.4 \pm 0.9$ & $2.2 \pm 1.0$ & 0.99 & 0.47 \\
\hline $\begin{array}{l}\text { Maximum predilatation balloon } \\
\text { pressure (atm) }\end{array}$ & $12 \pm 4$ & $12 \pm 6$ & $11 \pm 5$ & 0.86 & 0.48 \\
\hline Mean stent diameter (mm) & $2.8 \pm 0.4$ & $3.0 \pm 0.5$ & $3.0 \pm 0.6$ & 0.013 & $<0.001$ \\
\hline Mean stent length (mm) & $22 \pm 8$ & $23 \pm 9$ & $26 \pm 9$ & 0.27 & 0.005 \\
\hline Post-dilatation & $66(100)$ & $105(88)$ & $123(93)$ & 0.004 & 0.030 \\
\hline $\begin{array}{l}\text { Maximum post-dilatation balloon } \\
\text { diameter }(\mathrm{mm})\end{array}$ & $3.1 \pm 0.5$ & $3.1 \pm 0.8$ & $3.1 \pm 0.9$ & 0.48 & 0.53 \\
\hline $\begin{array}{l}\text { Maximum post-dilatation balloon } \\
\text { pressure (atm) }\end{array}$ & $16 \pm 4$ & $14 \pm 5$ & $15 \pm 5$ & 0.033 & 0.09 \\
\hline
\end{tabular}

Unless indicated otherwise, data are presented as the mean \pm SD or $n(\%)$. Abbreviations as in Table 1. 
into the lumen and, although covered, still transparently visible; Grade 2, stent struts embedded in the neointima, but translucently visible; Grade 3, stent struts fully embedded and invisible on angioscopy. ${ }^{\mathbf{1 2}}$ Heterogeneity of NIC has been defined previously..$^{13}$ Briefly, NIC was evaluated throughout the entire stented segments, and was judged as heterogeneous when differences in the NIC grade became apparent. Struts crossing the side branch and located in the overlapped segment were excluded from grading. In addition, stent edges were excluded from the heterogeneity analysis.

The yellow color was graded as follows: Grade 0, white; Grade 1, light yellow; Grade 2, yellow; Grade 3, intensive yellow. ${ }^{14}$ Thrombus was defined based on criteria adopted by the European Working Group on Coronary Angioscopy. ${ }^{15}$

\section{Statistical Analysis}

All results are expressed as mean $\pm \mathrm{SD}$, unless otherwise stated. Continuous variables with and without homogeneity of variance were analyzed by Student's t-test and Welch's t-test, respectively. Categorical variables were analyzed with Fisher's exact test for $2 \times 2$ comparisons. For more than $2 \times 2$ comparisons, the Mann-Whitney test was used. Statistical significance was defined as 2 -sided $\mathrm{P}<0.05$. All analyses were performed using IBM SPSS Statistics Version 24 (IBM Corp., Armonk, NY, USA).

\section{Results}

\section{Baseline Characteristics}

Patients' characteristics are presented in Table 1. There was a lower proportion of patients with hypertension in the O-SES than X-EES group, but a higher proportion of current smokers in the former group. There was also a higher frequency of patients with diabetes in the O-SES than S-EES group. Table 2 presents the medications used by the patients at baseline. Statin use was significantly more frequent in the O-SES group than in the other 2 groups. There were no significant differences in lesion characteristics different between the O-SES group and the other 2 groups (Table 3).

Data regarding the procedures undertaken are presented in Table 4. Although intravascular ultrasound was used less frequently in the O-SES group, optical coherence tomography (OCT) was more frequent in the O-SES than the other 2 groups. The O-SES group had a significantly smaller mean stent diameter and a higher frequency of post-dilation than the other 2 groups. Mean stent length was shorter in the O-SES than S-EES group. In addition, maximum post-dilation balloon pressure was higher in the O-SES than X-EES group.

\section{CAS Findings}

As reported in a previous article from our institution, ${ }^{\mathbf{1 4}}$ the estimated inter- and intraobserver $\kappa$ coefficients were 0.84 and 0.95 , respectively, for the dominant degree of NIC over the stent, 0.84 and 0.83 , respectively, for heterogeneity of NIC, 0.82 and 0.86 , respectively, for yellow color grade of the stented segment, and 0.93 and 1.0 , respectively, for the presence of intrastent thrombus.

There was no significant difference in mean follow-up duration for patients in the O-SES, X-EES, and S-EES groups (293 $\pm 36,300 \pm 39$, and $290 \pm 33$ days, respectively; $\mathrm{P}=0.21$ and $\mathrm{P}=0.60$ vs. $\mathrm{O}-\mathrm{SES}$, respectively). The dominant NIC grade was significantly lower in the O-SES than

\section{Dominant neointimal coverage grade}

(\%) 100

$\begin{array}{lll}100 & \text { O-SES versus X-EES: } P=0.25 & \text { O-SES } \\ \text { O-SES versrs S-EES: } P<0.001 & \text { X-EES } \\ 80 & & \text { S-EES }\end{array}$

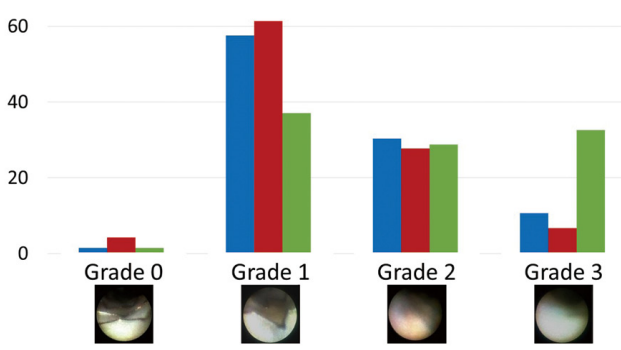

Figure 1. Dominant neointimal coverage grade with ultrathinstrut biodegradable-polymer sirolimus-eluting stents (O-SES), durable-polymer everolimus-eluting stents (X-EES), and biodegradable-polymer everolimus-eluting stents (S-EES). The dominant neointimal coverage grade was significantly lower in the O-SES than S-EES group $(P<0.001)$, but similar in the $\mathrm{O}-\mathrm{SES}$ and $\mathrm{X}$-EES groups $(\mathrm{P}=0.25)$.

\section{Heterogeneity of neointimal coverage}

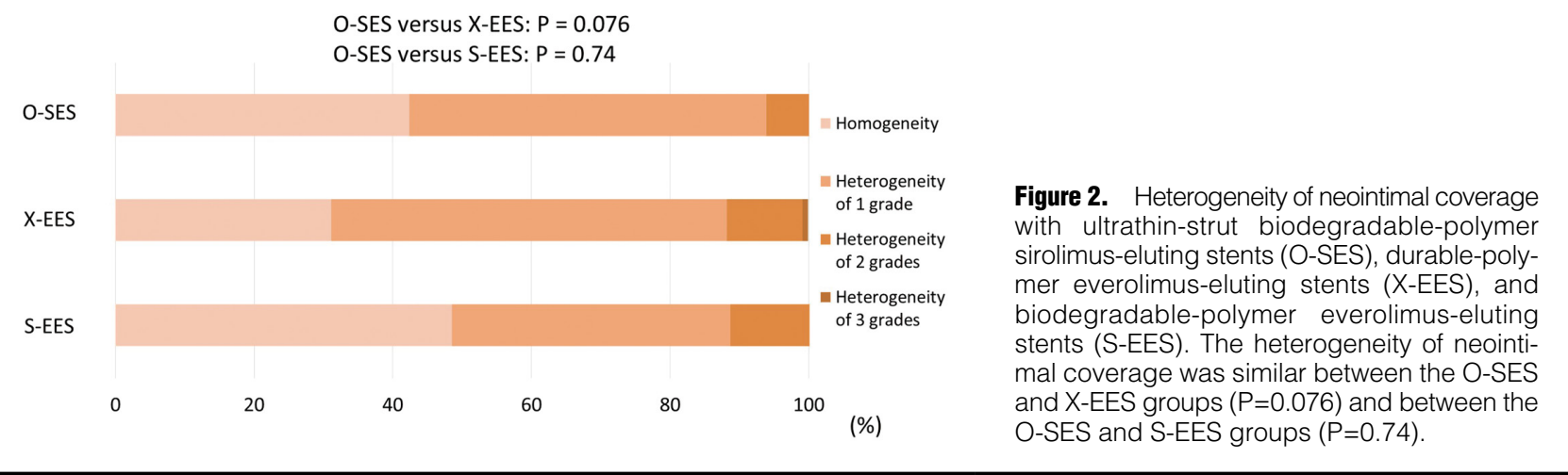




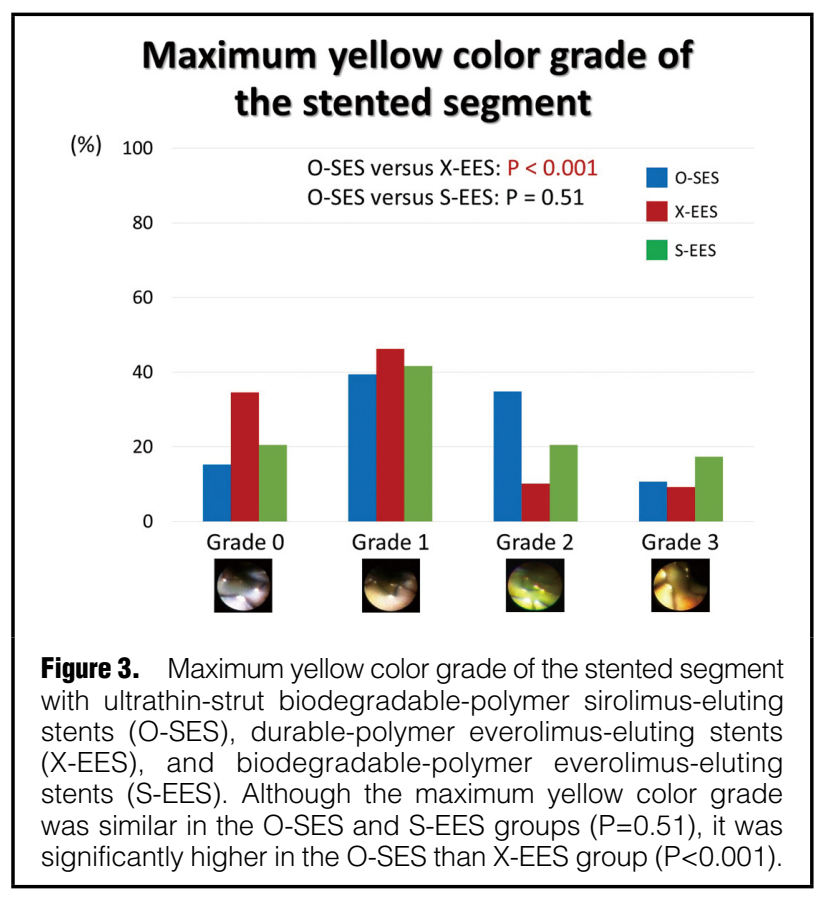

S-EES group $(\mathrm{P}<0.001)$, but was similar in the O-SES and $\mathrm{X}$-EES groups $(\mathrm{P}=0.25$; Figure 1$)$. NIC heterogeneity was similar in the O-SES and $\mathrm{X}$-EES groups $(\mathrm{P}=0.076)$ and in the $\mathrm{O}-\mathrm{SES}$ and $\mathrm{S}-\mathrm{EES}$ groups $(\mathrm{P}=0.74$; Figure 2). Although the maximum yellow color grade was similar in the O-SES and $\mathrm{S}-\mathrm{EES}$ groups $(\mathrm{P}=0.51)$, it was significantly higher in the O-SES than X-EES group $(\mathrm{P}<0.001$; Figure 3$)$. The incidence of thrombus adhesion was similar in the O-SES and X-EES groups $(27.3 \%$ vs. $18.5 \%$, respectively; $\mathrm{P}=0.076)$ and in the O-SES and S-EES groups $(27.3 \%$ vs. $20.5 \%$, respectively; $\mathrm{P}=0.74$; Figure 4).

\section{Discussion}

The findings of the present study are that, 10 months after stent implantation: (1) the dominant NIC grade was significantly lower in the O-SES than S-EES group, but similar in the O-SES and X-EES groups; (2) NIC heterogeneity and the incidence of thrombus adhesion were similar in all 3 groups; and (3) the maximum yellow color grade was similar in the O-SES and S-EES groups, but was significantly higher in the O-SES than X-EES group. To the best of our knowledge, this is the first report describing intravascular status evaluated by CAS 10 months after O-SES implantation comparing DP-DES with other BP-DES.

The EVOLVE II randomized trial showed that the absolute value of stenosis in the diameter of the stent segment was higher for S-EES than for DP everolimus-eluting stents. $^{\mathbf{8}}$ In addition, U-SES, a type of BP-DES, had a significantly larger late loss. ${ }^{7}$ It takes 3-4 months for the polymer of S-EES and U-SES to dissolve. ${ }^{7,20}$ Previous angioscopic reports had revealed that BP-DES, including S-EES and U-SES, had significantly higher dominant NIC grades than DP-DES 10-12 months after implantation, whereas NIC heterogeneity, maximum yellow color grade, and the incidence of thrombus adhesion were not significantly different between BP-DES and DP-DES. ${ }^{14,21}$ Similarly, the dominant NIC grade in the present study was

\section{Incidence of thrombus adhesion}

(\%) 100

O-SES versus $X$-EES: $P=0.17$

$O$-SES versus S-EES: $P=0.28$

80

60

20

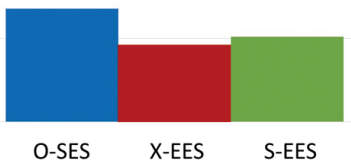

Figure 4. Incidence of thrombus adhesion with ultrathin-strut biodegradable-polymer sirolimus-eluting stents (O-SES), durable-polymer everolimus-eluting stents (X-EES), and biodegradable-polymer everolimus-eluting stents (S-EES). The incidence of thrombus adhesion was similar between the O-SES and X-EES groups (27.3\% vs. 18.5\%, respectively; $\mathrm{P}=0.076)$ and between the O-SES and $\mathrm{S}-\mathrm{EES}$ groups $(27.3 \%$ vs. $20.5 \%$, respectively; $P=0.74$ ). higher in the S-EES than X-EES group, although NIC heterogeneity, maximum yellow color grade, and the incidence of thrombus adhesion did not differ significantly. Although O-SES is a BP-DES, its dominant NIC grade in the present study was similar to that of the X-EES group, and was significantly lower than in the S-EES group. Using OCT, Karjalainen et al reported that O-SES provided slightly better stent strut coverage at 3 months than did DP zotarolimus-eluting stents. ${ }^{22}$ Thinner struts are smaller obstacles than thicker struts for the confluent endothelium layer and, as such, have faster integration into the vessel wall and re-endothelialization. ${ }^{23-26}$ Because it is ultrathin, the O-SES is likely to be covered by neointima earlier after implantation. Conversely, compared with X-EES, O-SES was found to be non-inferior for in-stent late lumen loss at 9 months. ${ }^{27}$ Mean neointimal thickness evaluated by OCT was also similar in the O-SES and X-EES groups in a subanalysis. ${ }^{27}$ Consistent with these results, the dominant NIC grade in the present study did not differ significantly between the O-SES and X-EES groups. Based on these results, we speculate that the ultrathin O-SES is likely to be covered relatively early after implantation, but NIC may not progress so rapidly thereafter, relative to S-EES. Differences in the duration of polymer dissolution would contribute to the differences in NIC seen between the O-SES and S-EES. The presence of polymer may induce arterial wall inflammation, delayed vascular healing, and long-term endothelial dysfunction. ${ }^{28}$ Although the polymer of BP-DES is completely degraded over time, there is a concern regarding potential inflammatory responses due to products of polymer degradation. ${ }^{29} \mathrm{O}-\mathrm{SES}$ has a BP that completely degrades over a period of 12-24 months. ${ }^{9}$ CAS findings 10 months after stent implantation in the present study were therefore from a time point before the O-SES polymer had completely dissolved, suggesting that arterial inflammation due to polymer degradation products may have inhibited the process of neointimal coverage. Therefore, in the present study, the dominant NIC grade of O-SES was compa- 
rable to that of X-EES and significantly lower than that of S-EES, which seems to make sense. In addition, it is necessary to further investigate the intravascular status 12-24 months after O-SES implantation, when the polymer is completely degraded.

In the present study, the maximum yellow color grade was significantly higher in the O-SES than X-EES group 10 months after stent implantation, although it was similar in the O-SES and S-EES groups. In general, angioscopically detected yellow plaque is considered to represent arteriosclerotic changes. A previous report noted that yellow plaque is commonly detected at the culprit lesions of acute coronary syndrome. ${ }^{30}$ In other studies, angioscopy and OCT showed that as the fibrous cap became thinner, the yellow color of the plaque became more intense. ${ }^{31,32}$ Higo et al reported that first-generation DES showed accelerated formation of yellow plaque 10 months after implantation. ${ }^{33}$ Previous histopathologic reports documented that abnormal vascular responses, including neoatherosclerosis, occurred when using first-generation DES, 2,3 which may have been contributing to the progression of yellow plaque. In the present study, the O-SES group had a significantly higher maximum yellow color grade than the $\mathrm{X}$-EES group. However, we were unable to determine whether this finding indicated neoatherosclerosis or underlying yellow plaque that had existed before stent implantation because we had not evaluated the yellow color grade at the time of stent implantation. It has been reported that inflammation occurs during the process of polymer degradation $^{\mathbf{3 4}, 35}$ and that inflammation promotes neoatherosclerosis. ${ }^{6}$ We hypothesize that neoatherosclerosis may be more easily promoted in the O-SES than X-EES group because the duration of polymer degradation in the former is relatively long and absorption was still ongoing at the time of CAS evaluation in the present study. Further investigations are needed to clarify this issue.

In terms of baseline patient characteristics, the O-SES group included a proportion of current smokers and a tendency for more patients with diabetes than the X-EES group. The absolute rates of acute coronary syndrome and hemodialysis were also higher in the O-SES group. From these data, it cannot be excluded that the O-SES group may have initially had more severe atherosclerosis than the $\mathrm{X}$-EES group and that this may be associated with the yellow color grade in the present study.

A reduction in strut thickness has been shown to mitigate thrombus formation. ${ }^{26}$ However, although the O-SES stent strut is ultrathin, the incidence of thrombus adhesion did not differ significantly between the 3 groups in the present study. Arterial healing is thought to be incomplete in the segment of the stent with thrombus adhesion. This is because such adhesion occurs in the initial phase of arterial healing after stent implantation. Later, a thrombus does not attach to the stented segment where arterial repair is complete because mature endothelial cells have antithrombotic effects. ${ }^{\mathbf{1 6}, 36}$ The O-SES polymer is still present 10 months after implantation, and arterial healing may still have been in progress at that time. Furthermore, previous CAS studies showed that the incidence of thrombus adhesion was higher at locations with a yellow color than at stent implantation site that were white. ${ }^{37}$ In addition, the rate of thrombus adhesion increased as the yellow color grade became more severe. ${ }^{30}$ The relatively high yellow color grade in the O-SES group in the present study may affect the incidence of thrombus adhesion and diminish the benefit of this ultrathin strut.

\section{Clinical Implications}

Even with the use of a BP, the O-SES resulted in an NIC similar to the X-EES and lower than the S-EES, but similar thrombus adhesion. Ten months after implantation, the dominant NIC grade was significantly lower in the O-SES than S-EES group, and neointimal proliferation was considered to be more strongly inhibited. Therefore, the restenosis rate may be lower in the O-SES than S-EES group. Conversely, it was considered that the vascular response to O-SES was similar to that to the X-EES during this phase, whereas the maximum yellow color grade was significantly higher in the O-SES group. Although the O-SES polymer is biodegradable, it is not completely degraded 10 months after implantation. Patients treated with an O-SES may have a reduced risk of vessel inflammation and progression of neoatherosclerosis at a later time, because the polymer is completely degraded only 24 months after implantation. Further investigations with longer-term data are desirable.

\section{Study Limitations}

This study has several limitations. First, it was a singlecenter, non-randomized, observational study. However, the sample size was sufficient to permit evaluation of the outcome and was comparable to previous CAS studies. Second, one of the reasons why CAS was not performed in all patients was because appropriate specialists were not available, making this a selection bias. Third, the CAS cohort in the present study was not composed of consecutive patients, which is another selection bias. Fourth, because this study was a retrospective and observational study, the timing of stent implantation differed among the 3 groups, which may have affected the baseline characteristics. In fact, some patient, lesion, and procedural background characteristics were different between the O-SES and other 2 groups. These differences could have influenced the CAS findings. The best way to overcome this inherent limitation would be propensity score matching for fair comparisons in this kind of study design. However, it was difficult to do such matching in the present study because the sample size was relatively small in each group, especially in the O-SES group. Fifth, different types of CAS catheters were used during the study period according to their availability. We cannot completely rule out the possibility that this affected the angioscopic findings somewhat, although we carefully analyzed angioscopic images. Sixth, nothing can be concluded from the findings regarding yellow color in the present study because we did not evaluate the yellow color grade at the time of stent implantation. Finally, CAS was not always able to evaluate the entire stented segment because of limitations to the CAS visual field, especially in angulated or tortuous lesions. However, in such cases, changing the guidewire sometimes improved the visual field. Further investigation is necessary.

\section{Conclusions}

O-SES provided NIC inhibition similar to X-EES, and a lower NIC grade than S-EES, despite being biodegradable. In addition, O-SES showed a similar degree of thrombus adhesion as X-EES or S-EES, suggesting similar thrombogenicity. 


\section{Acknowledgments}

The authors thank Takashi Sumikawa, Hiroki Oyama, Kazutoshi Ito, Yusuke Katagiri, Kohei Nanri, and Haruna Miyaguchi for their expertise in performing the CAS examinations.

\section{Sources of Funding}

This study did not receive any specific funding.

\section{Disclosures}

O.I. has received remuneration from Medtronic Japan and Boston Scientific Japan. T.M. has received a research grant from Abbott Vascular Japan. The remaining authors have no disclosures to report.

\section{IRB Information}

This study was approved by the Medical Ethics Committee of Kansai Rosai Hospital (Reference no. 2001025).

\section{Data Availability}

The deidentified participant data will not be shared.

\section{References}

1. Moses JW, Leon MB, Popma JJ, Fitzgerald PJ, Holmes DR, O'Shaughnessy C, et al. Sirolimus-eluting stents versus standard stents in patients with stenosis in a native coronary artery. $N$ Engl $J$ Med 2003; 349: 1315-1323.

2. Nakazawa G, Finn AV, Vorpahl M, Ladich ER, Kolodgie FD, Virmani R. Coronary responses and differential mechanisms of late stent thrombosis attributed to first-generation sirolimus- and paclitaxel-eluting stents. J Am Coll Cardiol 2011; 57: 390-398.

3. Nakazawa G, Otsuka F, Nakano M, Vorpahl M, Yazdani SK, Ladich E, et al. The pathology of neoatherosclerosis in human coronary implants: Bare-metal and drug-eluting stents. $J$ Am Coll Cardiol 2011; 57: 1314-1322.

4. Yano H, Horinaka S, Watahiki M, Watanabe T, Ishimitsu T. Five-year outcomes after first- and second-generation drug-eluting stent implantation in all patients undergoing percutaneous coronary intervention. J Cardiol 2019; 74: 169-174.

5. Otsuka F, Vorpahl M, Nakano M, Foerst J, Newell JB, Sakakura K, et al. Pathology of second-generation everolimuseluting stents versus first-generation sirolimus- and paclitaxeleluting stents in humans. Circulation 2014; 129: 211-223.

6. Otsuka F, Byrne RA, Yahagi K, Mori H, Ladich E, Fowler DR, et al. Neoatherosclerosis: Overview of histopathologic findings and implications for intravascular imaging assessment. Eur Heart J 2015; 36: 2147-2159.

7. Saito S, Valdes-Chavarri M, Richardt G, Moreno R, Iniguez Romo A, Barbato E, et al. A randomized, prospective, intercontinental evaluation of a bioresorbable polymer sirolimus-eluting coronary stent system: The CENTURY II (Clinical Evaluation of New Terumo Drug-Eluting Coronary Stent System in the Treatment of Patients With Coronary Artery Disease) trial. Eur Heart J 2014; 35: 2021-2031.

8. Kereiakes DJ, Meredith IT, Windecker S, Lee Jobe R, Mehta SR, Sarembock IJ, et al. Efficacy and safety of a novel bioabsorbable polymer-coated, everolimus-eluting coronary stent: The EVOLVE II Randomized Trial. Circ Cardiovasc Interv 2015; 8: e002372.

9. Jensen LO, Thayssen P, Maeng M, Ravkilde J, Krusell LR, Raungaard B, et al. Randomized comparison of a biodegradable polymer ultrathin strut sirolimus-eluting stent with a biodegradable polymer biolimus-eluting stent in patients treated with percutaneous coronary intervention: The SORT OUT VII trial. Circ Cardiovasc Interv 2016; 9: e003610.

10. Sakai S, Mizuno K, Yokoyama S, Tanabe J, Shinada T, Seimiya $\mathrm{K}$, et al. Morphologic changes in infarct-related plaque after coronary stent placement: A serial angioscopy study. J Am Coll Cardiol 2003; 42: 1558-1565.

11. Takano M, Mizuno K, Yokoyama S, Tanabe J, Shinada T, Seimiya K, et al. Changes in coronary plaque colour and morphology by lipid-lowering therapy with atorvastatin: Serial evaluation by coronary angioscopy. J Am Coll Cardiol 2003; 42: $680-686$.

12. Kotani J, Awata M, Nanto S, Uematsu M, Oshima F, Minamiguchi $\mathrm{H}$, et al. Incomplete neointimal coverage of sirolimus-eluting stents:
Angioscopic findings. J Am Coll Cardiol 2006; 47: 2108-2111.

13. Awata M, Nanto S, Uematsu M, Morozumi T, Watanabe T, Onishi T, et al. Heterogeneous arterial healing in patients following paclitaxel-eluting stent implantation: Comparison with sirolimus-eluting stents. JACC Cardiovasc Interv 2009; 2: 453-458.

14. Ishihara $\mathrm{T}$, Tsujimura $\mathrm{T}$, Okuno $\mathrm{S}$, Iida $\mathrm{O}$, Asai $\mathrm{M}$, Masuda $\mathrm{M}$, et al. Early- and middle-phase arterial repair following bioresorbable- and durable-polymer drug-eluting stent implantation: An angioscopic study. Int J Cardiol 2019; 285: 27-31.

15. den Heijer P, Foley DP, Hillege HL, Lablanche JM, van Dijk RB, Franzen D, et al. The "Ermenonville" classification of observations at coronary angioscopy: Evaluation of intra- and interobserver agreement. European Working Group on Coronary Angioscopy. Eur Heart J 1994; 15: 815-822.

16. Awata M, Kotani J, Uematsu M, Morozumi T, Watanabe T, Onishi T, et al. Serial angioscopic evidence of incomplete neointimal coverage after sirolimus-eluting stent implantation: Comparison with bare-metal stents. Circulation 2007; 116: 910-916.

17. Inoue $T$, Shinke $T$, Otake $H$, Nakagawa M, Hariki $H$, Osue $T$, et al. Neoatherosclerosis mural thrombus detection after sirolimus-eluting stent implantation. Circ J 2014; 78: 92-100.

18. Awata $\mathrm{M}$, Nanto $\mathrm{S}$, Uematsu $\mathrm{M}$, Morozumi $\mathrm{T}$, Watanabe $\mathrm{T}$, Onishi T, et al. Angioscopic comparison of neointimal coverage between zotarolimus- and sirolimus-eluting stents. $\mathrm{J} \mathrm{Am} \mathrm{Coll}$ Cardiol 2008; 52: 789-790.

19. JCS Joint Working Group. Guidelines for elective percutaneous coronary intervention in patients with stable coronary artery disease (JCS 2011) published in 2012: Digest version. Circ J 2013; 77: $1590-1607$.

20. Meredith IT, Verheye S, Dubois CL, Dens J, Fajadet J, Carrié $\mathrm{D}$, et al. Primary endpoint results of the EVOLVE trial: A randomized evaluation of a novel bioabsorbable polymer-coated, everolimus-eluting coronary stent. J Am Coll Cardiol 2012; 59: $1362-1370$.

21. Nojima Y, Adachi H, Ihara M, Kurimoto T, Okayama K, Sakata Y, et al. Impact of different coronary angioscopic findings on arterial healing one year after bioresorbable-polymer and second-generation durable-polymer drug-eluting stent implantation. J Cardiol 2020; 76: 371-377.

22. Karjalainen PP, Varho V, Nammas W, Mikkelsson J, Pietilä M, Ylitalo A, et al. Early neointimal coverage and vasodilator response following biodegradable polymer sirolimus-eluting vs. durable polymer zotarolimus-eluting stents in patients with acute coronary syndrome: HATTRICK-OCT trial. Circ J 2015; 79: $360-367$.

23. Foin N, Gutiérrez-Chico JL, Nakatani S, Torii R, Bourantas $\mathrm{CV}$, Sen S, et al. Incomplete stent apposition causes high shear flow disturbances and delay in neointimal coverage as a function of strut to wall detachment distance: Implications for the management of incomplete stent apposition. Circ Cardiovasc Interv 2014; 7: 180-189.

24. Joner M, Nakazawa G, Finn AV, Quee SC, Coleman L, Acampado $\mathrm{E}$, et al. Endothelial cell recovery between comparator polymerbased drug-eluting stents. J Am Coll Cardiol 2008; 52: 333-342.

25. Kolandaivelu K, Swaminathan R, Gibson WJ, Kolachalama VB, Nguyen-Ehrenreich KL, Giddings VL, et al. Stent thrombogenicity early in high-risk interventional settings is driven by stent design and deployment and protected by polymer-drug coatings. Circulation 2011; 123: 1400-1409.

26. Lee R, Foin N, Ng J, Allen J, Soh N, Ang I, et al. Early coverage of drug-eluting stents analysed by optical coherence tomography: Evidence of the impact of stent apposition and strut characteristics on the neointimal healing process. EuroIntervention 2016; 12: e605-e614.

27. Windecker S, Haude M, Neumann FJ, Stangl K, Witzenbichler B, Slagboom T, et al. Comparison of a novel biodegradable polymer sirolimus-eluting stent with a durable polymer everolimus-eluting stent: Results of the randomized BIOFLOW-II trial. Circ Cardiovasc Interv 2015; 8: e001441.

28. Virmani R, Guagliumi G, Farb A, Musumeci G, Grieco N, Motta $T$, et al. Localized hypersensitivity and late coronary thrombosis secondary to a sirolimus-eluting stent: Should we be cautious? Circulation 2004; 109: 701-705.

29. van der Giessen WJ, Lincoff AM, Schwartz RS, van Beusekom HM, Serruys PW, Holmes DR Jr, et al. Marked inflammatory sequelae to implantation of biodegradable and nonbiodegradable polymers in porcine coronary arteries. Circulation 1996; 94: $1690-1697$

30. Ueda Y, Ohtani T, Shimizu M, Hirayama A, Kodama K. Assessment of plaque vulnerability by angioscopic classification of 
plaque colour. Am Heart J 2004; 148: 333-335.

31. Takano M, Jang IK, Inami S, Yamamoto M, Murakami D, Okamatsu K, et al. In vivo comparison of optical coherence tomography and angioscopy for the evaluation of coronary plaque characteristics. Am J Cardiol 2008; 101: 471-476.

32. Kubo T, Imanishi T, Takarada S, Kuroi A, Ueno S, Yamano T, et al. Implication of plaque colour classification for assessing plaque vulnerability: A coronary angioscopy and optical coherence tomography investigation. JACC Cardiovasc Interv 2008; 1: $74-80$.

33. Higo T, Ueda Y, Oyabu J, Okada K, Nishio M, Hirata A, et al. Atherosclerotic and thrombogenic neointima formed over sirolimus drug-eluting stent: An angioscopic study. J Am Coll Cardiol Img 2009; 2: 616-624.

34. Malle C, Tada T, Steigerwald K, Ughi GJ, Schuster T, Nakano
M, et al. Tissue characterization after drug-eluting stent implantation using optical coherence tomography. Arterioscler Thromb Vasc Biol 2013; 33: 1376-1383.

35. Gori T, Jansen T, Weissner M, Foin N, Wenzel P, Schulz E, et al. Coronary evaginations and peri-scaffold aneurysms following implantation of bioresorbable scaffolds: Incidence, outcome, and optical coherence tomography analysis of possible mechanisms. Eur Heart J 2016; 37: 2040-2049.

36. Schwartz RS. Pathophysiology of restenosis: Interaction of thrombosis, hyperplasia, and/or remodelling. Am J Cardiol 1998; 81: $14 \mathrm{E}-17 \mathrm{E}$.

37. Oyabu J, Ueda Y, Ogasawara N, Okada K, Hirayama A, Kodama K. Angioscopic evaluation of neointima coverage: Sirolimus drug-eluting stent versus bare metal stent. Am Heart $J$ 2006; 152: $1168-1174$ 